\title{
Las prácticas genocidas y los crímenes contra la humanidad en Colombia: el caso de la Unión Patriótica y los líderes sociales en el postacuerdo (2016)
}

\author{
Genocidal practices and crimes against humanity in \\ Colombia: the case of the Unión Patriótica (Patriotic \\ Union) and social leaders in the post-agreement (2016)
}

\author{
Karina Johana Martínez Jiménez \\ Magíster en Derechos Humanos, \\ Interculturalidad y Desarrollo \\ Universidad Pablo de Olavide, Sevilla-España \\ Correo electrónico: kmartinezj25@gmail.com
}

\footnotetext{
Cómo citar este artículo:

Martínez, K. (2021). Las prácticas genocidas y los crímenes contra la humanidad en Colombia: el caso de la Unión Patriótica y los líderes sociales en el post-acuerdo (2016). Revista de la Facultad de Derecho y Ciencias Políticas, 51(135), 489-516. doi: https://doi.org/10.18566/rfdcp.v51n135.a09
}

Recibido: 13 de febrero de 2020

Aprobado: 29 de enero de 2021 


\section{Resumen}

A partir de una perspectiva sociojurídica, histórica y crítica de los derechos humanos, el presente trabajo busca comprender los fenómenos implicados en los crímenes contra la humanidad y las prácticas genocidas en el contexto colombiano. Para lo anterior se recurre, por un lado, a una doctrina de derecho internacional público; y, por otro, a los aportes de los estudios críticos sobre genocidio. Esto último, sobre todo considerando el contexto histórico latinoamericano. Posteriormente, se examina la aplicabilidad de las categorías expuestas a dos casos concretos: la Unión Patriótica (finales del siglo XX y comienzos del XXI), y los líderes sociales en el postacuerdo (2016). Se concluye que el exterminio del movimiento político Unión Patriótica tiene elementos significativos tanto de crímenes contra la humanidad, como de prácticas genocidas; mientras que el caso de los líderes sociales se comprende en términos del crimen contra la humanidad.

\section{Palabras clave}

Crímenes contra la humanidad; prácticas genocidas; Unión Patriótica; líderes sociales.

\section{Abstract}

From a socio-legal, historical and critical perspective of human rights, this work seeks to understand the phenomena involved in crimes against humanity and genocidal practices in the Colombian context. For the above, recourse is had to, on the one hand, a doctrine of public international law; and, on the other, to the contributions of critical studies on genocide. The latter is given special consideration due to the Latin American historical context. Subsequently, the applicability of the categories exposed to two specific cases is examined: the Unión Patriótica or Patriotic Union (late 20th century and early 21st), and social leaders in the post-agreement (2016). It is concluded that the extermination of the political movement Unión Patriótica has significant elements of both crimes against humanity and genocidal practices; while the case of social leaders is understood in terms of crime against humanity.

\section{Keywords}

Crimes against humanity; genocidal practices; Unión Patriótica (Patriotic Union); social leaders. 


\section{Introducción}

En Colombia, uno de los factores que alimentan la continuidad de la violencia y la victimización ha sido la lógica amigo-enemigo, producto de más de cinco décadas de conflictos internos con múltiples complejidades y actores. Factores como la poca eficacia en la ejecución de políticas para detener la criminalidad pueden dar lugar a la comisión de crímenes internacionales. En el caso colombiano, los grupos armados ilegales no solo continúan sus acciones, sino que han surgido nuevos grupos delincuenciales (incluso, tras procesos de desmovilización). Este es un escenario donde la población más vulnerable a la victimización sigue siendo la rural, campesina, étnica, de escasos recursos, pero también otros grupos sociales como los políticos. Históricamente, la construcción del enemigo común en Colombia ha girado en torno a las guerrillas de izquierda. Pero tal identificación también se ha trasladado a grupos de oposición política, líderes sociales, defensores de derechos humanos, movimientos sociales y, en fin, todo aquel que resulte contrario a los intereses de las organizaciones criminales que poseen cierto control territorial, político o económico.

El presente trabajo busca la comprensión del crimen contra la humanidad y las prácticas genocidas. Sobre todo, por la necesaria protección de aquellos grupos sociales o políticos que sostienen 0 han sostenido alguna posición contra-hegemónica (entiéndase, partidos o movimientos políticos opuestos a los tradicionales; y ciudadanos en ejercicio de liderazgo social, ligados al mejoramiento de algún ámbito de su comunidad). Luego, se estudia la aplicabilidad de las categorías frente a dos casos en Colombia: el caso Unión Patriótica, y lo que sucede con los líderes sociales en el contexto postacuerdo. Los casos se estudiarán identificando los elementos que los configuran dentro de la tipificación de crímenes contra la humanidad, y de prácticas genocidas, en lo concerniente al movimiento político Unión Patriótica ${ }^{1}$. Lo anterior, mediante una metodología de análisis documental, desde una perspectiva crítica en derechos humanos ${ }^{2}$, en tanto que esta última involucra aspectos como lo histórico, sociológico, o discursivo; es decir, la búsqueda de un enfoque integral de análisis.

\footnotetext{
1 La calificación del exterminio de la Unión Patriótica como genocidio político ha sido ampliamente investigada, véase Ortiz (2006; 2009), Gómez Suárez (2013). También, sobre genocidio político Dudley (2008), Huertas y Cáceres (2015).

2 Para una teoría crítica que indaga por la integralidad en la comprensión de los derechos humanos,
} véase Herrera Flores (2008), Gándara (2013). 
Este enfoque no pretende atender al fenómeno de genocidio y crímenes contra la humanidad como categorías exclusivas del ámbito jurídico autorreferencial. O, en otras palabras, no procura una contribución a la doctrina penalista, aunque necesariamente debe recurrir a este tipo de interpretaciones. Más bien, persigue el estudio de estos fenómenos como categorías de análisis crítico, histórico, y sociojurídico. Análisis que, además de acudir a interpretaciones jurídicas, aterriza el contexto social en el que ocurren los casos; esto es, atiende a la realidad social de la población afectada. Pues bien, tanto el crimen contra la humanidad como el genocidio, más allá de lo jurídico autorreferencial, adquieren sentido a partir de un "marco sociocultural" (Ortiz, 2001, p. 273). En últimas, la preocupación aquí planteada por revisar estos casos de violencia en términos de crímenes contra la humanidad (también llamados de lesa humanidad) y prácticas genocidas, gira en torno a reconocer y exigir los derechos de la población afectada. Más aun cuando en el panorama iberoamericano de la segunda mitad del siglo XX han sido múltiples los casos de exterminio a grupos políticos (Olasolo, Chinchón y Rodríguez, 2019, p. 670).

\section{Los crímenes contra la humanidad y las prácticas genocidas: del Estatuto de Roma a los estudios críticos sobre genocidio}

Como es sabido, luego del contexto de la Segunda Guerra Mundial en Europa, se desarrolla más ampliamente el concepto de crímenes contra la humanidad. Sobre todo, durante la segunda mitad del siglo XX (Benería y Sarasúa, 2011), con un despliegue más concreto en el Estatuto de Roma de 1998, de la Corte Penal Internacional (Ambos, 2013). Pero, ¿cuál es la diferencia entre el crimen contra la humanidad y otros delitos llamados comunes? Y, por otra parte, ¿qué se entiende por prácticas genocidas desde una visión crítica de estudios sobre el genocidio?

\section{Los crímenes contra la humanidad a partir del Estatuto de Roma de 1998}

Uno de los rasgos distintivos del crimen contra la humanidad frente a delitos comunes es "el carácter generalizado o sistemático del ataque contra la población civil” (Bolívar, 2011, p. 168). Al mismo tiempo, se habla de una intervención o tolerancia por parte del "poder político" (Bolívar, 2011, p. 168), o de una “tolerancia institucional” (Fernández, Sánchez, Ortega, 2015, 
p. 471). Luego, entre los elementos constitutivos de este tipo de crimen se encuentran (a) la naturaleza generalizada o sistemática de los ataques, (b) la dirección del ataque (población civil), (c) la tolerancia - de facto o de iure- de las instituciones. Por su parte, se ha reconocido que los perpetradores pueden ser agentes estatales o no, y los actos delictivos pueden cometerse tanto en contextos bélicos como en tiempos de paz (Fernández, Sánchez, Ortega, 2015, p. 471). Desde el Estatuto de Roma, los tipos delictivos como el asesinato deben corresponderse con un elemento de contexto (Ambos, 2013), el cual comprende un ataque generalizado o sistemático en contra de una población civil, con conocimiento del victimario. Dicho de otro modo, los crímenes contra la humanidad implican un patrón de selectividad ${ }^{3}$. Estos se desarrollan en una situación de acción u omisión por parte de las autoridades (Gil, 2017).

En dicho contexto, el perpetrador cuenta con medios que no tiene el autor de un delito común, de donde puede derivar el éxito y la impunidad en la comisión repetida de la conducta criminal. En relación con la continuación en el tiempo por causa de la tolerancia u omisión por parte de las instituciones, Ambos (2013) expone que:

Si se trata, como ya se ha dicho, de la protección contra los peligros particulares de la comisión múltiple o repetida de delitos, el apoyo activo o al menos tolerado por las autoridades (de facto), entonces dicha política de apoyo o tolerancia, - es decir, el contexto de un ataque general- aumenta el efecto destructivo del acto individual y el riesgo o peligro para la víctima. Compárese, por ejemplo, el caso de un asesinato ordinario en el curso de un robo y el asesinato de un oponente político. En el primer caso, no hay apoyo oficial o la tolerancia de la muerte. En el último caso, este amplio apoyo o tolerancia aumenta el riesgo de la víctima potencial, escuda a los responsables de la persecución y podría transformar el asesinato común en un CLH. (Ambos, 2013, p.113).

La sistematicidad no solo se entiende en cuanto a que responde a una planificación metódica, sino que, además, es posible por el poder de actuación que tienen los perpetradores en un entorno permisivo. Por su parte, el carácter generalizado tiene que ver con un número significativo de víctimas. La comisión múltiple de actos (entendida como el carácter generalizado), y la política de organización o planificación (sistematicidad), hacen parte del contexto del

3 El patrón de selectividad o sistematicidad quiere decir que el ataque se dirige de manera planificada y con premeditación hacia determinado grupo social (Ambos, 2013). 
crimen contra la humanidad (Ambos, 2013). De manera que lo sistemático tiene que ver con una dimensión cualitativa, mientras que lo generalizado, con una cuantitativa (Ambos, 2013, pp.103-104; Gil, 2016, p. 205) (véase Ilustración 1).

Ilustración 1. Contexto crimen contra la humanidad.

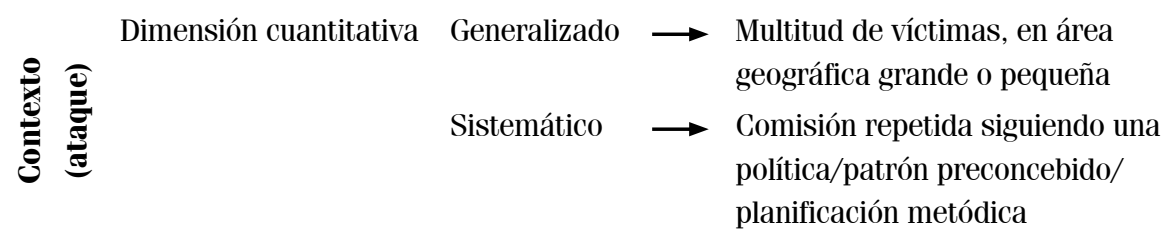

Fuente: Elaboración propia.

En cuanto al victimario, puede ser un ente estatal u organización criminal con capacidad política o de planeación. Dicha organización puede cometer actos de tal magnitud por varias circunstancias: por poseer un poder de iure o de facto en un territorio, por la tolerancia estatal, por poseer una estructura tal, que es casi imposible llegar a los organizadores, o también por poseer un gran poder político, social, económico, o estructural (Liñán, 2015; 2017). Lo que disminuye las probabilidades de que se castigue a los autores intelectuales de la organización criminal. La impunidad, entonces, es posible por cuenta de factores como inacción o tolerancia frente a estos crímenes ${ }^{4}$. Así las cosas, la continuación en el tiempo persiste, en tanto que los sistemas internos de protección no desarrollan o ejecutan efectivamente las garantías para la prevención de estos hechos.

Según investigaciones de la doctrina jurídica, el crimen contra la humanidad y el genocidio guardan tanto elementos en común como diferenciadores (Liñán, 2019; Olasolo, Chinchón y Rodríguez, 2019). Entre las similitudes se destaca el objeto del ataque (población civil), un contexto de violencia

\footnotetext{
$4 \quad$ Uno de los elementos que hace que este tipo de crímenes sean cometidos es la tolerancia por parte del Estado. Existen pues dos tipos de tolerancia: de iure o de facto. La primera tiene que ver con la actitud de un régimen totalitario donde no se puede confiar en la justica; y la segunda se da, por ejemplo, cuando "grupos rebeldes" tienen el control político sobre un territorio. En este último caso, desaparece la aplicación de la justicia o simplemente, los actores responsables de estos crímenes están fuera de ella (Gil, 2003).
} 
generalizada (gran proporción) y sistemática (organización para...). Pero una de las diferencias significativas tiene que ver con la protección de un bien jurídico "supraindividual” en el caso del genocidio, esto es, la existencia de grupos humanos. Lo que no sucede con el crimen contra la humanidad. En este sentido, un elemento diferenciador sería lo que algunos llaman como el "elemento subjetivo trascendente", que, en el caso del genocidio, es la intención de destruir parcial o totalmente a un grupo humano. 0 , lo que es lo mismo, una “intención genocida” (Gil, 2019; Olasolo, Chinchón y Rodríguez, 2019).

De otro lado, además de un patrón de selectividad o generalidad, hay que atender a los grupos protegidos por estas categorías. La posición política o ideológica de las víctimas es uno de los elementos que cohesiona la identidad grupal, por lo menos desde la perspectiva de potenciales victimarios. En el caso de la violencia sistemática en contra de grupos políticos, se necesita un estudio más allá de la tipificación convencional, pues reducirlo a esta tiende a desestimar las bases materiales e históricas que hay detrás de los eventos, y, en consecuencia, las soluciones al problema.

\section{Las prácticas genocidas: aproximación desde los estudios críticos sobre genocidio}

Desde los inicios de organismos internacionales como las Naciones Unidas, se ha mostrado preocupación por el fenómeno del genocidio. En la resolución 96 (I) de $1946^{5}$ se expresó la necesaria atención que debía tener el genocidio y se puso de manifiesto su carácter de crimen de derecho internacional. En sus literales, se concibió como la destrucción “total o parcial” de grupos raciales, religiosos, o políticos: “...El genocidio es un crimen del derecho internacional... por motivos religiosos, raciales, o políticos, o de cualquier otra naturaleza” (Res. 96 (I), 11 diciembre 1946, p. 128).

Posteriormente, en la resolución 260 A (III), de 19486 , se aprobó el texto de la Convención para la prevención y sanción del delito de genocidio, donde finalmente se habla de este fenómeno como aquel constituido por actos (matanza, lesión a la integridad física o mental, etc.) que tengan como motivación la destrucción total o parcial de grupos nacionales, étnicos, raciales o religiosos (art. II, res. 260 A III, 1948). Lo que dejó de contemplar el

5 Resolución 96 (I) de 1946, accesible en https://undocs.org/es/A/RES/96\%28I\%29 (9/02/2021).

6 Resolución 260 A (III) de 1948, accesible en https://undocs.org/pdf?symbol=es/A/RES/260(III) $(09 / 02 / 2021)$ 
móvil político, aunque expertos involucrados en el proyecto defendieron hasta último momento dicho móvil. Para los adeptos a esta última posición, una de las razones para la inclusión de los grupos políticos exponía que "los grupos políticos han sido tradicionalmente perseguidos con tanta virulencia como el resto de grupos protegidos” (Olasolo, Chinchón y Rodríguez, 2019, p. 666). Pese a los argumentos planteados por defensores de esta última posición, finalmente la protección a estos grupos fue excluida de la convención.

Así, aunque la Convención para la prevención y sanción del delito de genocidio de 1948 limita la identidad de los grupos protegidos a los nacionales, étnicos, raciales, o religiosos, el debate sobre la inclusión de otros grupos sigue tanto vigente como controversial (Olasolo, Chinchón y Rodríguez, 2019). Se ha planteado, por ejemplo, que históricamente los grupos victimizados también han tenido vínculos de otro tipo. Juristas como Sánchez Legido manifiestan que:

Curiosamente, los grupos nacionales, étnicos, raciales o religiosos, cuya destrucción parece constituir el objetivo genocida, resultan ser a menudo y al mismo tiempo, opositores al régimen político o ideológico del Estado, con lo cual es difícil evitar cierto solapamiento entre el genocidio y los crímenes contra la humanidad ${ }^{7}$. (Fernández, et al., 2015, p. 471).

Si bien la categoría de crimen contra la humanidad responde oportunamente al caso de los grupos políticos, llega a carecer de una “intención genocida”, esta última entendida como la intención por parte del victimario, de la destrucción total o parcial de un grupo humano (Olasolo, Chinchón y Rodríguez, 2019).

En cuanto al aporte de los estudios críticos sobre genocidio, sobre todo desde la corriente de sociólogos como Daniel Feierstein o Marcia Esparza, el debate llama la atención sobre la intencionalidad del fenómeno atendiendo a la realidad latinoamericana. Pero, además, teniendo en cuenta las desigualdades sociales, políticas y económicas que caracterizan a la región (Esparza, 2009; Shaw, 2013; Feierstein, 2014, 2015). Dichos elementos suelen tener un papel significativo en la distinción de grupos sociales.

Lo más revelador que aporta el concepto de genocidio frente a los crímenes de lesa humanidad, parece ser, entonces, el elemento intencional que se

$7 \quad$ Sobre el texto final de la Convención de 1948, la limitación en la protección de los grupos fue necesaria a causa de las diferentes posturas y en aras de una aceptación generalizada que no pusiera en riesgo su consecución (Fernández, Sánchez, y Ortega, 2015, p .469). 
concibe en el primero. Ello representa la riqueza de la noción, pues aporta sentido al elemento subjetivo de este tipo de crímenes internacionales. A juicio del sociólogo, Daniel Feierstein: "El concepto de crímenes contra la humanidad no logra contemplar la riqueza y potencialidad presente en el concepto de genocidio, que refiere al intento de destrucción de un grupo y no meramente de población civil indiscriminada” (Feierstein, 2015, p.111). Esta intencionalidad se convierte en una de las diferencias más significativas frente a un exterminio en el marco de los crímenes contra la humanidad.

En cuanto a los grupos objeto de protección desde la Convención de 1948, autores como Garretón (2001) han anotado: "Lamentablemente no se incluyeron los grupos culturales o políticos, como aparecía en los primeros proyectos, produciéndose el efecto que en la discusión subrayó el delegado de Francia: en el futuro, dijo, todos los genocidios serán por motivos políticos” (Garretón, 2001, p. 26). Pero, la preocupación por la protección de los grupos políticos ha sido objeto de gran interés por parte de ordenamientos jurídicos latinoamericanos. Ejemplo de ello, es el Artículo 101 del Código Penal Colombiano, o la sentencia C-177/01 de la Corte Constitucional de Colombia, que confirman la validez de la extensión hacia los grupos políticos (Olasolo, Chinchón y Rodríguez, 2019). Y es que, si se recurre a los acontecimientos históricos como fuente de conocimiento sobre los exterminios, el factor político ha acompañado el comportamiento de la violencia que ha azotado por décadas a la región latinoamericana (Esparza, Huttenbach, y Feierstein, 2009):

The legal notion of genocide has remained unchanged regarding what basically constitutes this crime. In the international treaties and even in the Rome Statute (Art. 6), genocide continues to be associated with a number of serious events, from the forced relocation of children from one group to another, up to the killing of members of a group. However, when scholars indicate what typifies this crime, they only include national, ethnic, racial, and religious groups, leaving out political ones, which have been the most affected in the twentieth century and in what has elapsed of the twenty-first. (Esparza, Huttenbach, y Feierstein, 2009, p.XII)

En cuanto a la tipificación internacional, Feierstein argumenta, que la idea del genocidio como expresión de conflictos tribales entre identidades distintas, tiende a simplificar la complejidad de los fenómenos. Y que, además, para un análisis riguroso del genocidio, se requiere tener en cuenta tanto la estrategia de poder, como el modo en que opera hacia el conjunto social (Feierstein, 2016). Pese a su composición heterogénea, los grupos políticos tienen 
características propias que los hacen claramente diferenciables, y es que, de manera semejante a los grupos religiosos, poseen creencias o ideas sobre una postura particular (Olasolo, Chinchón y Rodríguez, 2019).

A partir de una perspectiva antropológica y sociológica, la identidad o pertenencia a un grupo no necesariamente debe interpretarse como un estado inmóvil; sino más bien como producto de distinguir entre lo semejante y lo diferente en un contexto sociocultural determinado (Ortiz, 2001, p. 274). Los elementos cohesionadores que le dan identidad a un grupo político, en este caso, comprenden desde la adhesión - temporal o no - a un partido político, hasta el marco ideológico y objetivos políticos compartidos. En el caso de un movimiento político alternativo, este promueve perspectivas y programas diferentes a los partidos tradicionales. Existen, entonces, unos referentes de identidad definidos, que son asociados desde el interior de los miembros del grupo, pero también desde la óptica del reconocimiento de los demás (Ortiz, 2001).

Al aterrizar el estudio al contexto histórico sobre los casos de exterminio en América Latina, se observa que el siglo XX estuvo marcado por un proyecto anticomunista que, de la mano de Estados Unidos, promovió golpes de Estado y luchas internas. En el panorama global, durante los años sesenta del siglo pasado - en el proceso descolonizador en África y Asia - , Estados Unidos y sus aliados extendieron el ideario anticomunista, acompañándolo de una estrategia contrainsurgente y antisubversiva. Al parecer, dicha estrategia se había desarrollado en la guerra de Argelia por Francia, con el fin de combatir los gobiernos nacionalistas y antiimperialistas (Roitman, 2017, p.12). La estrategia en mención no se hizo esperar en América Latina, región no ajena a los efectos de la Guerra Fría. Se llevaron a cabo acciones desestabilizadoras o apoyando golpes de Estado. En tal proyecto estratégico existió un rasgo representativo: "En todos los casos está presente el asesinato político, el exilio y la persecución a los partidos comunistas” (Roitman, 2017, p.12).

Tener en cuenta los contextos en los que surge la violencia, contribuye a entender la continuidad de las formas de violencia sistemática. Es entonces oportuno atender a las complejas relaciones sociales, políticas y económicas que históricamente han tenido lugar en estos contextos. En opinión de Esparza: "Without investigating the Latin American experience of extreme forms of political violence, the global study of genocide remains incomplete” (Esparza et al., 2009, pp.1-2). 
Como ha sido ampliamente estudiada, la violencia sistemática durante el siglo pasado en la región latinoamericana estuvo marcada por una estrategia “anticomunista”. Donde existía un escenario en el que las víctimas de los crímenes contra la humanidad, la persecución de grupos sociales, tenían la coincidencia de integrar lo que se ha llamado como la "clase popular", desde partidos comunistas, hasta profesores rurales o comunidades indígenas ${ }^{8}$ (Esparza et al., 2009; Roitman, 2017) .

La historia latinoamericana ofrece ejemplos de la existencia de sujetos opresores - estatales, en los casos de Argentina, Chile o Guatemala - , cuyos proyectos políticos fueron capaces de privar los derechos fundamentales de aquellos grupos con intereses opuestos. Estos grupos no solo se han caracterizado por un rasgo de identidad ${ }^{9}$ permanente, sino que han sido un complejo de distintos actores, como líderes políticos de oposición, sociales, o étnicos. Desde esta perspectiva, el objetivo último de la práctica genocida fue destruir la identidad de un grupo para imponer la de un opresor (Feierstein, 2016, p. 250) ${ }^{10}$.

Ahora bien, y retomando el concepto de crímenes contra la humanidad, el énfasis se encuentra mayormente en el contexto y objeto del ataque, esto es, en el ataque sistemático y generalizado contra una población civil; con un conocimiento de la dirección del ataque hacia esta última. Lo que se observa en esta tipificación es la desaparición de la “intención de destrucción” del grupo, que en cambio sí se encuentra presente en la noción de genocidio. Si bien la noción de crimen contra la humanidad protege a grupos humanos más amplios, carece de un elemento subjetivo, en otras palabras, la intención genocida de acabar con la existencia de un grupo ${ }^{11}$ (Olasolo, Chinchón y Rodríguez, 2019).

8 Marcia Esparza argumenta que, tal como ocurrió en Chile en 1907, y con "la violencia" de 1940 en Colombia, las víctimas suelen representar a los más pobres de la sociedad (Esparza et al., 2009, p.9).

9 Frente a lo problemático de pensar los grupos sociales como entes homogéneos (cuando incluso dentro de los propios miembros existen divergencias), autores como Christopher Powell, proponen la denominación de "red social" para mostrar la complejidad de los actores inmersos (Gómez Suárez, 2013, p.184). La red social es lo que permite calificar desde fuera a un colectivo. O, en otras palabras, el cómo se ve desde fuera el individuo de acuerdo con ciertos elementos, y en su relación con los otros.

10 El autor define las prácticas genocidas apelando a la preocupación de Lemkin como "los modos sistemáticos de destrucción de la identidad nacional" o "la destrucción de la identidad del grupo oprimido" (Feierstein, 2016, p. 251). No obstante, el propio Lemkin manifestó dudas sobre la protección de grupos políticos por la falta de permanencia de identidad; pero, además, por la mayor vulnerabilidad de los grupos finalmente protegidos, en un contexto de negociaciones que podía poner en peligro la protección de estos últimos (Olasolo, Chinchón y Rodríguez, 2019).

11 Sobre la intención de destruir al grupo en el delito de genocidio, véase, Gil (2019). 
Por su parte, la noción de prácticas genocidas atiende a la intención de destruir un grupo humano. Ello responde así al elemento subjetivo de la intencionalidad del victimario. Es importante entender los casos de exterminio acudiendo a la categoría de crimen contra la humanidad, pero, además, es necesario mostrar la finalidad de la práctica social o su lógica de ejecución (Feierstein, 2016). Este concepto busca atender a aquellos móviles criminales cuyo objetivo es reprimir o acabar con el sector social que está siendo victimizado. Si esto se deja de lado para los grupos políticos mediante la sola calificación de crímenes contra la humanidad, el elemento subjetivo tenderá a ser aún más subjetivo, esto es, se tendría que aludir a "la maldad intrínseca de los perpetradores" (Feierstein, 2016, p. 258).

En el caso latinoamericano, la polarización social y la marginalización de unos grupos responde a un estado de cosas donde intervienen factores diversos y complejos como el político, económico, de clase, y por supuesto, étnico. En dicho contexto, los grupos de izquierda o alternativos, así como movimientos sociales y populares han sido percibidos históricamente como una amenaza para el proyecto capitalista de algunas regiones. Véase, por ejemplo, los casos de masacres como la "semana trágica" de 1919 en Argentina; el etnocidio de 1932 en El Salvador; el periodo de violencia política con la represalia de militar 1931 en Trujillo, Perú; el abatimiento de los mineros huelguistas de Iquique a manos del ejército chileno en 1907; o la masacre de las bananeras de 1928, en Colombia.

Para el caso del movimiento político Unión Patriótica, aunque a partir de la Convención de 1948 no puede hablarse del término genocidio (sí desde el ordenamiento jurídico colombiano), se observa la existencia tanto de la comisión de crímenes contra la humanidad por sus rasgos de generalidad y sistematicidad, como una intención de destruir al grupo. Esto último encajaría con el elemento subjetivo de una práctica genocida. Hay autores que han llamado al fenómeno acontecido como una "coyuntura de violencia genocida", entendida como un contexto en el que distintos actores criminales pudieron tener intereses o un proyecto en común. Lo anterior sería la causa para la victimización de ciertos grupos sociales (Gómez Suárez, 2013). 


\section{Algunas cuestiones sobre la criminalización de la diferencia en el siglo XX}

En Colombia, los actores dela violencia han conformado un conjunto complejo que involucra no solo sectores del crimen organizado ${ }^{12}$-como paramilitares, narcotraficantes, bandas criminales- sino también amplios sectores de la sociedad colombiana, de la institucionalidad, como las Fuerzas Armadas, y, por supuesto, las guerrillas de izquierda (Farc, Ejército de Liberación Nacional - ELN, entre otras) (Gómez Isa, 2008). Para algunos historiadores, en medio de toda esta estructura de violencia, la historia de Colombia, sobre todo a partir de la segunda mitad del siglo XX, se ha caracterizado por ir perfeccionando el discurso del enemigo subversivo, del anticomunismo (Estrada, 2015).

Sobre la criminalización en contra de los movimientos políticos de izquierda en el siglo XX, Gonzalo Sánchez Gómez expone lo siguiente:

El discurso homogenizante y excluyente de la "Guerra Fría", sumado a la oposición a la apertura política iniciada por el gobierno de Belisario Betancur (1982-1986) sirvieron como telón de fondo a una ecuación estigmatizante que equiparaba la militancia política de izquierda con una militancia armada subversiva. Las fuerzas disidentes pasaron, así, a convertirse en objetivos militares y el escenario político terminó copado por la dinámica bélica. El desenlace, como se sabe, fue el asesinato de centenares, si no de miles de militantes del Partido Comunista Colombiano (PCC), de la Unión Patriótica (UP), del Movimiento Obrero Independiente Revolucionario (MOIR), del Frente Popular y de A Luchar, ante el grueso de una sociedad e instituciones pasivas frente al clamor y la denuncia de las víctimas. (CNMH, 2014, 13)

El discurso de criminalización de finales del siglo pasado parecía fortalecer y radicalizar una opinión pública en contra de movimientos políticos alternativos que hacían frente a la política tradicional. Pero la criminalización no solo se ha ejercido en contra de los simpatizantes o militantes de la izquierda política colombiana, sino que se ha trasladado a los que defienden los derechos humanos. Para algunos, se ha llegado a establecer la asociación "militante

Al parecer, la respuesta por parte de las instituciones frente a grupos ilegales como los paramilitares se ha caracterizado desde la indiferencia cómplice, omisión, simpatía y justificación de su existencia, hasta el respaldo explícito por medio de la financiación, acompañamiento y apoyo logístico. En general ha operado la lógica de que el "enemigo de mi enemigo es mi amigo" (Valencia y Zúñiga, 2015). 
de izquierda - defensor de los derechos humanos - subversivo" (Centro Nacional de Memoria Histórica, 2014, p. 13).

\section{¿Tolerancia de facto en Colombia?}

Uno de los factores que favorece la comisión reiterada de los crímenes contra la humanidad es la tolerancia de facto. Esta última se entiende como aquellas situaciones de hecho en las que, pese a la existencia de normatividad, existe una acción ineficaz por parte de las instituciones para combatir las violaciones de derechos humanos (Chinchón, 2012; CINEP et al., 2018). Este elemento permite la continuación de los crímenes en el tiempo. Situación que es posible cuando existe, por ejemplo, un control territorial por parte de grupos ilegales armados, donde la justicia y los instrumentos jurídicos tienen un alcance limitado (Gil, 2003).

En el contexto colombiano los grupos paramilitares, que en sus orígenes nacen como formas reactivas provenientes de distintos actores sociales, entre los que se encuentran narcotraficantes, ganaderos, latifundistas, sectores de las Fuerzas Armadas (Valencia y Zúñiga, 2015; Koessl, 2015), no parecen ser un asunto del pasado (El País, 2017; BBC, 2019; 2020). Lo cierto es que el paramilitarismo ha sido uno de los agentes protagonistas en el desarrollo y continuación de la violencia (Koessl, 2015), junto a otros grupos armados al margen de la ley.

En cuanto a los grupos paramilitares, se ha reconocido que estos nacieron como organizaciones de autodefensa antisubversiva, pero que pronto descubrieron la necesidad de gobernar, y establecieron nuevas formas de control en los territorios (Gutiérrez y Barón, 2006, p. 270). Pese a que ya existían grupos paramilitares para la protección de grupos económicos, como el de las esmeraldas, dichas organizaciones paramilitares se autorreconocieron como una fuerza contrainsurgente, que no solo combatía guerrillas, sino que, según ellos, procuraban una "limpieza social” (Gómez Isa, 2008). 0, en otras palabras, tenían como fin acabar con poblaciones que ellos consideraban indeseables. Respecto de su relación con las fuerzas estatales,

No es secreto que, al menos en sus orígenes, y en casos más recientes y no precisamente esporádicos, se haya dado colaboración entre las fuerzas legales del ejército y las bandas paramilitares para combatir a lo que se podría ver como un enemigo común: las guerrillas y las redes de colaboración que construyen. (Gómez Isa, 2008, p. 25). 
Eduardo Pizarro Leongómez (2003) ha descrito las relaciones entre el Estado y los paramilitares como ambivalentes ${ }^{13}$. Relaciones que, desde su creación en los 70, han ido desde la convivencia pragmática, apoyo, hasta la indiferencia (Pizarro, 2003, p.10). Al respecto, véanse los testimonios de denuncias sobre las masacres ocurridas en Remedios y Segovia el siglo pasado. En declaraciones ante la prensa, los párrocos Jorge Mina Balbín y Gabriel Yepes Yepes, declararon responsabilidad del ejército en los hechos y acompañaron la primera etapa de la investigación judicial (CNMH, 2014, p. 44). Frente a lo sucedido, el párroco Yepes afirmó (citado en CNMH, 2014) que “desde el comando del Batallón Bomboná, que tiene su sede en Segovia, se planearon estos horrendos crímenes” (CNMH, 2014, p. 45).

Sobre las cuatro masacres ocurridas en Remedios y Segovia ${ }^{14}$ y la implicación de agentes de las Fuerzas Armadas de Colombia, se ha conocido que:

Han sido proferidos varios fallos judiciales, en ocasiones contradictorios, al igual que procesos disciplinarios sobre la actuación de integrantes de la fuerza pública. Con base en los procesos seguidos a las cuatro masacres se podría afirmar que hay un implicado en calidad de perpetrador común: agentes de la fuerza pública y también una víctima común: civiles en estado de indefensión, pertenecientes a la izquierda política. (CNMH, 2014, pp.16-17)

A partir de esta histórica vinculación estatal - sea por acción u omisiónes posible comprender la comisión de crímenes contra la humanidad en el país ${ }^{15}$. Aquí la tolerancia de facto propia del contexto de los crímenes contra la humanidad es viable por cuenta de una compleja relación entre los grupos criminales y el Estado, una acción ineficaz por parte de este último en la ejecución de una política criminal efectiva, y un gobierno que no ha podido

13 Para explicar las posibles causas de dichas relaciones, Pizarro expone hipótesis como las siguientes: la histórica debilidad del Estado colombiano de controlar todas las zonas, la estrategia de desdoblamiento constante de los grupos guerrilleros, y/o la consecuente utilización de estos grupos ilegales por parte de las élites locales (Pizarro, 2003, p.10).

14 Masacres en las que fueron victimizados una cantidad significativa de militantes o adeptos al movimiento Unión Patriótica. Al respecto véase el informe del $\mathrm{CNMH}, 2014$ : Silenciar la democracia. Las masacres de Remedios y Segovia 1982-1997. Disponible en http://www. centrodememoriahistorica.gov.co/2014-01-29-15-08-26/silenciar-la-democracia-las-masacres-deremedios-y-segovia (31/07/19).

15 En el caso de los paramilitares, resultan relevantes los términos de tolerancia o impunidad de facto (Gil, 2003). Los grupos paramilitares ejercen un control en el territorio, y pese a los intentos de políticas para la desmovilización, así como los avances en la justicia, parece que el Estado no ha logrado una verdadera desintegración de las redes o los autores intelectuales de estos crímenes. En muchos casos se debe a la ausencia estatal en las zonas, situación que históricamente ha dado pie al desarrollo de grupos guerrilleros, tanto de izquierda como de derecha (Pizarro, 2003). 
llegar a todos los territorios -ni en materia institucional, ni en garantías de derechos humanos- (Pizarro, 2003).

\section{El caso de la Unión Patriótica (1984-2002)}

El exterminio del movimiento político Unión Patriótica (entiéndase UP), que nace como sector heterogéne ${ }^{16}$ de izquierda, no solo evidencia la comisión de crímenes enmarcados en el derecho internacional en territorio colombiano, sino que, además, representa serios obstáculos para el libre desarrollo del proyecto democrático y pluralista de país ${ }^{17}$. En sus inicios, la Unión Patriótica se abrió paso como un frente común que representaba la unidad popular, y un camino para la transformación política, un proyecto en el que podían converger los distintos actores políticos que perseguían objetivos de cambio para el país (CNMH, 2018). Aunque la UP fue el resultado de uno de los puntos negociados en los acuerdos de paz de La Uribe con las Fuerzas Armadas Revolucionarias de Colombia, Farc ${ }^{18}$, los desmovilizados de dicha guerrilla representarían solo un integrante más del nuevo movimiento y así lo dejó saber el propio grupo insurgente en su momento ${ }^{19}$. La UP se configuró, entonces, como un movimiento amplio y pluralista, y así lo demostró, por ejemplo, la participación de los distintos sectores en su primer congreso (CNMH, 2018, pp. 39-40).

Esta confluencia había sido posible por cuenta de los intereses compartidos, por ejemplo, de reforma democrática, ya que uno de los objetivos que se venían gestando desde los años 80 por los distintos actores locales, era el desarrollo de un movimiento amplio que pudiera romper con el histórico bipartidismo del Frente Nacional ${ }^{20}$ (CNMH, 2018; Saldarriaga y Gómez, 2015).

16 Pese a que la plataforma inaugural del movimiento estuvo relacionada con un sector de la izquierda subversiva, el proyecto representaba una especie de coalición de sectores políticos mayoritariamente de los movimientos políticos alternativos (CNMH, 2018).

17 Lo cierto es que, y siguiendo la línea argumentativa de Cepeda (2006, p. 101), la eliminación violenta de los movimientos ideológicos alternativos ha sido una constante en la historia del país.

18 Acuerdo de paz llevado a cabo entre la guerrilla de las Farc y el gobierno de Belisario Betancur en 1984. El compromiso principal era el cese al fuego y la búsqueda de alternativas políticas para los desmovilizados y para el país (CNMH, 2018).

19 Así fue expuesto en la guía organizacional de 1985, donde se hablaba de un movimiento amplio compuesto por las masas populares y las distintas capas intermedias de la población $(\mathrm{CNMH}$, 2018, p. 88).

20 El Frente Nacional (1958-1974) se conoce como el acuerdo político de alternancia de poder bipartidista entre conservadores y liberales que marcó los años 60 en el país. El plebiscito para la creación del bloque nace luego de los acuerdos bipartidistas de Benidorm y Sitges, que, más que una reforma del Estado representó un pacto entre los dos partidos tradicionales. Sucedió en este contexto, el desarrollo de grupos al margen de la ley (Gómez Isa, 2008, p. 20). En los años 
Cabe destacar que el movimiento tuvo representación política sobre todo en distintos sectores rurales, mientras que para las principales urbes se observó un crecimiento más paulatino (CNMH, 2018).

\section{El exterminio en contra de la Unión Patriótica (1984-2002)}

El Observatorio de Memoria y Conflicto, como componente del Centro Nacional de Memoria Histórica (CNMH), ha documentado entre el periodo de surgimiento y finalización del movimiento de la Unión Patriótica (1984-2002), un total de 4153 víctimas, tanto de asesinato como de otras modalidades. Así lo expone el CNMH en relación con las formas de victimización: "Entre estas, 3122 fueron víctimas de asesinato selectivo, 544 lo fueron de desaparición forzada, 478 fueron víctimas de asesinatos en masacres, 4 secuestradas y 3 más en otras modalidades de violencia” (CNMH, 2018, p.108) (véase Ilustración 2).

Ilustración 2. Víctimas fatales UP 1984-2002.

\begin{tabular}{|c|c|c|c|c|c|}
\hline \multicolumn{6}{|c|}{$\begin{array}{c}\text { VÍCTIMAS 1984-2002 } \\
\text { Total: } 4153\end{array}$} \\
\hline Modalidad & $\begin{array}{l}\text { Asesinato } \\
\text { selectivo }\end{array}$ & $\begin{array}{l}\text { Desaparición } \\
\text { forzada }\end{array}$ & $\begin{array}{c}\text { Asesinato en } \\
\text { masacres }\end{array}$ & Secuestro & Otros \\
\hline $\begin{array}{l}\text { Número de } \\
\text { víctimas }\end{array}$ & 3122 & 544 & 478 & 4 & 3 \\
\hline
\end{tabular}

En relación con las víctimas sobrevivientes o "no fatales”, el CNMH (2018) ha documentado un total de 2049 víctimas en distintas modalidades ${ }^{21}$. Según dicha fuente, se tiene en el periodo que comprende de 1984 a 2002, por lo menos un total de 6202 víctimas. De las cuales 2049 son no fatales y más de 3000lo son, es decir, víctimas de asesinato o de desaparición forzada. Incluso, hay quienes afirman que el registro de los casos aumenta si se tiene en cuenta

60 y 70 existe lo que se ha denominado un conflicto de "baja intensidad", que se caracteriza por constantes combates entre guerrillas y ejército; y posteriormente, en los 80 los niveles de violencia se dispararon (Gómez Isa, 2008).

21 Datos extraídos del Observatorio de Memoria y Conflicto del CNMH. Un subregistro proveniente de la corporación Reiniciar, ha reportado 1098 víctimas de desplazamiento forzado y exilio, 353 en modalidad de amenaza, 249 de tentativa de homicidio para el periodo 1984-2002 (CNMH, 2018, p. 108). 
el periodo posterior a la suspensión de la personería jurídica de la UP, ya que luego de 2002 continuaron los casos de violencia ${ }^{22}$.

Estos hechos se entienden en términos de crímenes contra la humanidad, pues la victimización en sus distintas modalidades evidencia un patrón de selectividad, donde se han documentado casos no solo de amenazas, sino también de tortura hacia los integrantes del movimiento. Más aún, los casos de asesinatos cerca de las viviendas de las víctimas mediante ataques sicariales encajan con un patrón de seguimiento a las víctimas. Por su parte, el factor cuantitativo demuestra un exterminio que comprende más de 3000 víctimas fatales. Según lo documentado en el informe del CNMH (2018), el número de víctimas cuyo derecho a la vida fue vulnerado, es superior a los 3600 casos. Ello, sumado a otras modalidades de violencia. En este caso no solo se evidencia una intención de destrucción mediante el homicidio, sino que la utilización de modalidades de violencia como la persecución ${ }^{23}$, son un reflejo más de la intención que tenían los perpetradores de acabar con el movimiento.

\section{Los crímenes contra la humanidad y las prácticas genocidas en el caso Unión Patriótica}

El caso ocurrido con la Unión Patriótica ha suscitado pronunciamientos desde distintos órganos, tanto en el país como por organismos internacionales. Se han pronunciado desde la Fiscalía General de la Nación, entes de Naciones Unidas en Colombia, hasta la Comisión Interamericana de Derechos Humanos (Castellanos y Barragán, 2016). Y se destaca el informe de 2018 por parte del Centro Nacional de Memoria Histórica, donde se ha hecho un trabajo de recopilación de datos y testimonios sobre el caso.

Pese a la documentación significativa, no existe un consenso definitivo entre lo que denuncian las víctimas, sobrevivientes, defensores de derechos humanos o académicos, por una parte, y lo que ofrece el sistema convencional internacional por otra. Respecto de los primeros, aducen un hecho de

22 La documentación aportada por las distintas organizaciones varía de una a otra, también respecto del periodo de muestra. En cuanto a las víctimas fatales en periodos posteriores a 2002, el Observatorio de Memoria y Conflicto ha documentado entre 2003-2016 cerca de 64 asesinatos y desapariciones forzadas. Por su parte, en cuanto a las víctimas no fatales, la Corporación Reiniciar ha identificado 1148 entre el periodo de 2003-2006 (CNMH, 2018, p.108).

23 Entiéndase "persecución" en virtud del artículo 7.2.g del Estatuto de Roma, como privación intencional de los derechos fundamentales en función de la identidad de un grupo. En este sentido, la persecución es la única modalidad que tiene un móvil discriminatorio en la categoría de crímenes contra la humanidad (Gil, 2016). 
genocidio político (CNMH, 2018), mientras que desde el derecho internacional público, tal categoría resulta problemática. Es claro que, desde el marco jurídico internacional, la utilización del concepto de genocidio en el caso de la Unión Patriótica no tendría cabida por pertenecer a un grupo excluido de la protección. No obstante, desde una perspectiva sociológica, es posible hablar de "prácticas genocidas", ya que existe una intención de acabar u oprimir al grupo (Fierestein, 2016). Así como es posible hablar de un genocidio político desde la legislación colombiana. Si hay un rasgo que lo identifica con el elemento subjetivo genocida es la intención de acabar con el movimiento. No por menos las cifras y testimonios documentados por las distintas investigaciones han demostrado el interés de los perpetradores por acabar con las víctimas en tanto su condición de militantes o incluso simpatizantes del movimiento político (CNMH, 2018).

Entre las posturas que debaten sobre la categoría de genocidio en este caso, se encuentra la línea de quienes califican el fenómeno como un genocidio político $^{24}$ (Cepeda, 2006; Saldarriaga y Gómez, 2015) por una parte; o como producto de una coyuntura política genocida, por otra (Gómez Suárez, 2013) ${ }^{25}$. Según la primera posición, se tiene que el estatus radicaría en aspectos como la intención de destrucción en perjuicio de las víctimas en tanto que integrantes de un grupo humano específico (movimiento político de izquierda). En la segunda posición, se trataría de un bloque perpetrador que, en una relación intersubjetiva, identifica al otro como enemigo, creando alianzas temporales y cambiantes para la destrucción de un enemigo en común²6.

En suma, la comisión de crímenes contra la humanidad es una categoría que responde al caso mencionado, pues posee elementos caracterizadores como la sistematicidad, la generalidad e incluso la tolerancia de facto o incapacidad institucional para acabar con la coyuntura de violencia acaecida. Al mismo

24 Hay quienes acuden a los principios del derecho por cuanto su cualidad de atentado contra la dignidad humana y el alto número de víctimas asesinadas o desaparecidas. Lo que demuestra una intención de acabar con un movimiento que proponía una política de oposición (Saldarriaga y Gómez, 2015, p.132).

25 A diferencia de Cepeda (2006), Gómez Suárez (2013) propone dejar a un lado el principio de intencionalidad y más bien enfocarse en los discursos de las relaciones o coyunturas geopolíticas, que sostienen el proyecto común de los victimarios.

26 Esta línea pone énfasis en unas circunstancias en la que los perpetradores identifican un objetivo en común y crean alianzas heterogéneas. Verbigracia, en el caso de la UP, distintos actores legales e ilegales estuvieron involucrados en los hechos. De ahí que, para evitar una posición sesgada respecto de los perpetradores 0 , en otras palabras, para evitar sostener la responsabilidad de un único victimario, estos pueden ser entendidos como la articulación de "un bloque perpetrador que aglutina coaliciones violentas regionales" (Gómez Suárez, 2013, p. 185). 
tiempo, desde otra perspectiva de análisis socio histórico, puede hablarse de prácticas genocidas por cuanto que existe una intención de destrucción de un proyecto político alternativo claramente identificable.

\section{El caso de los líderes sociales luego del Acuerdo de Paz de 2016}

Desde inicios del siglo XXI, la situación de los defensores y las defensoras de derechos humanos se convirtió en un tema tan relevante para organismos internacionales como Naciones Unidas, que la llevó a crear la figura del relator especial sobre la situación de las y los defensores de derechos humanos ${ }^{27}$. Hoy, más que nunca, esta preocupación continúa vigente, y se necesita de una efectiva protección de los derechos fundamentales ante los estados de vulnerabilidad de dichos grupos sociales. La construcción de una identidad sobre este grupo social aumenta la vulnerabilidad y lo expone a un tipo de coyuntura de violencia: un enemigo común para potenciales victimarios.

En Colombia, luego de la firma del Acuerdo de Paz de $2016^{28}$ los asesinatos no cesaron ${ }^{29}$. Pese a que, durante las campañas electorales de 2018, la Oficina del Alto Comisionado de las Naciones Unidas para los Derechos Humanos (entiéndase, OACNUDH) registró una disminución de las acciones violentas

\footnotetext{
Véase, https://www.ohchr.org/sp/Issues/SRHRDefenders/Pages/SRHRDefendersIndex.aspx (07/09/19).

28 En 2016 la guerrilla de las Fuerzas Armadas Revolucionarias de Colombia-Ejército del Pueblo (Farc) y el gobierno de Juan Manuel Santos signaron el Acuerdo Final para la Terminación del Conflicto y la Construcción de una Paz Estable y Duradera.

29 Por ejemplo, en la etapa preelectoral, la OACNUDH registró el asesinato de tres personas que pertenecían al partido político Fuerza Alternativa Revolucionaria del Común (OACNUDH, 2019). El Sistema de Alertas Tempranas (SAT) de la Defensoría del Pueblo emitió 52 informes de riesgo durante 2017, en los que la población civil se vio en situación alta vulnerabilidad ante la presencia de grupos armados ilegales. Entre los principales departamentos en alto riesgo estaban Antioquia, Bolívar, Cauca, Cesar, Norte de Santander, entre otros. Véase Vigésimo Quinto Informe del Defensor del Pueblo al Congreso de la República, accesible en http://www.defensoria.gov.co/ public/pdf/XXV-Informe-del-Defensor-del-Pueblo-al-Congreso-Parte-II.pdf (31/08/19) 89-107. Por otra parte, otras organizaciones registraron una tendencia general a la baja en víctimas mortales, pero una tendencia al aumento de los asesinatos hacia líderes sociales y defensores de derechos humanos. Hay quienes registran un total, 343 casos de asesinatos desde el 1 de enero de 2016 hasta 31 de julio de 2018 (CINEP et al., 2018). Por último, la Fiscalía General de la Nación manifestó mediante nota de prensa, que en el contexto postacuerdo (desde 2016 hasta 2019), ha logrado avanzar en la investigación de al menos 177 casos de los 302 que ha reportado Naciones Unidas. Accesible en https://www.fiscalia.gov.co/colombia/noticias/fiscalia-avanza-en-la-investigacion-yjudicializacion-de-homicidios-contra-lideres-sociales/ (26/08/19).
} 
(OACNUDH, 2019), las cifras de asesinatos de líderes sociales ${ }^{30}$ o defensores de derechos humanos -y otros movimientos- en etapa postacuerdo continuaron sumando víctimas.

La OACNUDH en Colombia, para el informe sobre el periodo $2018^{31}$, registró 110 asesinatos de defensores de derechos humanos. Allí, un $27 \%$ representa comunidades étnicas -indígenas, afrodescendientes-. Con una concentración significativa de casos en departamentos como Antioquia, Cauca, o Norte de Santander, llamadas “zonas de alto riesgo”. Se resaltó, también, que más del $90 \%$ de los casos tuvieron lugar en regiones donde persiste la falta de derechos básicos para la comunidad, como el derecho a la justicia, los económicos, sociales, culturales y ambientales. Situación que da pie a los altos índices de pobreza y consecuentemente el surgimiento de economías ilegales al mando de grupos armados (OACNUDH, 2019).

Por otra parte, el Sistema de Alertas Tempranas (SAT) de la Defensoría del Pueblo para el informe de Riesgo 010-2017 ${ }^{32}$ documentó entre el 1 de enero de 2016 y el 5 de marzo de 2017, al menos 150 asesinatos contra líderes sociales y defensores de derechos humanos. También advirtió la presencia de por lo menos 500 amenazas hacia líderes sociales, de las cuales 61 representaban amenazas colectivas (Defensoría del Pueblo, 2017).

Se ha destacado como una de las causas de vulnerabilidad la "respuesta inadecuada o tardía” frente a los informes de riesgo de entidades como la

30 Un líder o lideresa social puede entenderse como "una persona que cuenta con reconocimiento de su comunidad por conducir, coordinar o apoyar procesos o actividades de carácter colectivo que afectan positivamente la vida de su comunidad, mejoran y dignifican sus condiciones de vida o construyen tejido social" (CINEP et al., 2018, p. 9). De manera similar, puede entenderse por defensor de derechos humanos cualquier persona que defiende los derechos humanos independientemente de la organización a la que pueda pertenecer (OACNUDH, 2019). Ambos estatus pueden ser independientes, pero en muchos casos van relacionados. Por ejemplo, un líder comunitario puede ejercer labores de defensa de los recursos naturales frente a una multinacional, o gestionar procesos de reparación o restitución de tierras, o en general, apoyar la gestión en materia de derechos fundamentales, etc. De hecho, entes como la Defensoría del Pueblo en Colombia han agrupado ambas categorías (CINEP et al., 2018). Otro tipo de liderazgo tiene que ver con movimientos políticos y sociales, como el caso de Marcha Patriótica, que también ha registrado un número significativo de miembros asesinados, y que en 2018 cambia su estatus y se convierte en coordinadora política y social de organizaciones (CINEP et al., 2018).

31 Informe A/HRC/40/3/Add.3 accesible en https://www.hchr.org.co/index.php/informes-ydocumentos/informes-anuales/9017-informe-del-alto-comisionado-de-las-naciones-unidaspara-los-derechos-humanos-sobre-la-situacion-de-derechos-humanos-en-colombia-durante-elano-2018 (28/08/19).

32 Informe especial de riesgo: "violencia y amenazas contra los líderes sociales y los defensores de derechos humanos. Accesible en http://desarrollos.defensoria.gov.co/desarrollo1/ABCD/bases/ marc/documentos/textos/INFORME_ESPECIAL_LIDERES_30-03-17_(1).pdf (31/08/19). 
defensoría, así como la persistente tolerancia en los casos. Lo que permite la continuidad de las conductas delictivas (Defensoría del Pueblo, 2017). En la Alerta Temprana 026-2018 de la defensoría, como seguimiento al informe del año anterior, dicha entidad publicó una cifra de 282 asesinatos durante el 1 de enero de 2017 hasta el 27 de febrero de $2018^{33}$ (Defensoría del Pueblo, 2018).

De otra parte, según el Instituto de Estudios para el Desarrollo y la Paz (INDEPAZ) $^{34}$, desde suscrito el Acuerdo en 2016 a julio de 2019 se registraron 137 excombatientes asesinados y cerca de 623 líderes sociales y defensores de derechos humanos, entre los que se encuentran comunidades étnicas, campesinos ambientalistas, comunales, sindicalistas o defensores PNIS. De tal cifra, 252 corresponderían al periodo de 2018, donde se destacan departamentos como Antioquia, Cauca, Norte de Santander, entre otros (INDEPAZ, 2019).

En este contexto, se observa una violación sistemática de los derechos humanos, donde las lesiones se han dirigido hacia aquella población civil que ejerce algún tipo de liderazgo en la transformación de las condiciones de sus territorios. Es en este sentido que el grupo social adquiere identidad y representa un perfil específico para los perpetradores. Cuando las víctimas se encuentran liderando o participando de procesos comunitarios o de defensa de los derechos humanos se convierten en actores protagonistas en sus comunidades. Este ejercicio representa potencialmente obstáculos para la consecución de los objetivos de grupos criminales en ejercicio del poder y control territorial, económico o político de las zonas. Dicho contexto parece dar lugar a la existencia de una política criminal que se construye a partir de aquello que se opone a los intereses en juego, una distinción entre lo semejante y lo diferente.

El papel que representan los líderes, defensores y defensoras de derechos humanos puede ir en contra de los intereses de las organizaciones criminales que aún controlan ciertas zonas del país -ya sea por cuenta de una incapacidad estatal o por una tolerancia de facto-. Pero también persiste el riesgo hacia aquellos militantes de partidos alternativos que, en muchas ocasiones, ejercen este tipo de acción social -o que simplemente militan en los partidos-. Pese a que las luchas de los líderes son de carácter multidimensional, todas estas

Accesible en http://www.defensoria.gov.co/es/nube/destacados/7076/Alerta-temprana-026-2018es-una-nota-de-seguimiento-al-informe-de-Riesgo-010-2017.htm?_s=dia_agua (31/08/19).

34 Accesible en http://www.indepaz.org.co/wp-content/uploads/2019/08/Informe-parcial-Julio-262019-Indepaz-Marcha-Cumbre.pdf (29/08/19). 
tienden a transformar y mejorar las condiciones de vida de las comunidades en las que se hallan (CINEP et al., 2018). Sobre este asunto, se ha identificado que:

Las acciones y luchas más evidenciadas de las víctimas registradas se centran en: defensa de los derechos a la tierra y el territorio, veeduría y denuncia de crímenes de actores hegemónicos, denuncias de despojo de tierras, de actos de corrupción de funcionarios estatales, de presencia de actores armados, de reclutamiento forzado y de microtráfico. Otras víctimas hacían oposición a megaproyectos económicos, de explotación o de industrias extractivas (...) hacían defensa de derechos sexuales y reproductivos o trabajaban en proyectos de sustitución de cultivos de uso ilícito y otros referentes a la implementación del Acuerdo de Paz entre el Estado y la antigua guerrilla de las Farc--EP. (CINEP et al., 2018, p.211) $)^{35}$

En estas circunstancias de violencia, es posible hablar en términos de crímenes contra la humanidad, ya que los ataques se han dirigido hacia la población civil en ejercicio de alguna actividad política o social. Su actividad más (re)conocida puede tener relación con los móviles de las agresiones en su contra, y el número de víctimas da cuenta de una generalidad de casos.

Aunque los datos varían de unos organismos a otros, puede observarse tanto la sistematicidad, plan criminal, como la generalidad o el alto número de víctimas. Asimismo, un contexto de ineficacia o incapacidad institucional permite la reiteración de este tipo de conductas y la vigencia del control de ciertos territorios por parte de organizaciones criminales. Las víctimas pueden ser identificadas, no necesariamente como grupo homogéneo, pero sí como una población con actividades de tipo social o política. La ejecución de planes y seguimiento a las víctimas se puede ver, por un lado, en un contexto de discursos estigmatizadores en su contra, y por otro, en cuanto a que muchos casos de asesinato han sido cometidos en sus viviendas, lugares de trabajo, o cerca a estos (CINEP et al., 2018) ${ }^{36}$.

Al final, si desde las instituciones se niega que se trata de crímenes contra la humanidad, y limita el tratamiento de los actos de violencia sistemática a

35 También se han visto significativamente afectados, desde la firma del Acuerdo, individuos pertenecientes a colectivos de activistas para el derecho de las víctimas, y líderes de restitución de tierras (CINEP et al., 2018).

36 En la jurisprudencia de la Corte Penal Internacional puede encontrarse, que la sistematicidad puede deducirse también por factores como las circunstancias históricas, el contexto político, la propaganda mediática, o por la existencia de grupos militares autónomos (CINEP et al., 2018, p.163) 
delincuencia común, pueden llegar a minimizarse los esfuerzos por combatir este tipo de violencia.

\section{Conclusiones}

1. A lo largo del trabajo se ha hecho referencia a la categoría de crímenes contra la humanidad, por un lado, y las prácticas genocidas por otro. Esto último a partir de una perspectiva sociológica y crítica de los derechos humanos. El objetivo ha sido comprender los fenómenos de crímenes contra la humanidad y las prácticas genocidas en el contexto colombiano en relación a dos casos particulares. Para lo anterior ha sido necesario un análisis de tipo documental en cuanto a los aportes tanto del derecho internacional público, como de los estudios críticos sobre genocidio. Se ha podido concluir la aplicabilidad de ambas categorías para el caso del movimiento político Unión Patriótica. Y, por su parte, la comisión de crímenes contra la humanidad en el caso de líderes sociales en el postacuerdo.

2. Puede observarse cómo el motivo político ha sido el caracterizador de las prácticas genocidas en contra de la UP. Ello, por cuanto que representa un grupo social claramente identificable; esto es, un partido político con marco ideológico diferente al predominante en los partidos tradicionales. Las distintas formas de violencia y criminalización hacia el movimiento demuestran la intencionalidad del exterminio en su contra.

3. Los datos extraídos del Centro Nacional de Memoria Histórica permiten ver las cualidades de crímenes de derecho internacional. La sistematicidad, reflejada en la identificación del grupo por parte de los victimarios y consecuentemente, el ejercicio de un proyecto criminal; y la generalidad, por cuenta de las más de cuatro mil víctimas en distintas modalidades, sin olvidar las amenazas y estigmatizaciones de las que fueron objeto muchos de sus integrantes, como ha sido documentado en el informe del CNMH (2018).

4. Por su parte, el alto número de asesinatos en contra de líderes sociales y defensores de derechos humanos representa un contexto en el que la comisión de crímenes contra la humanidad sigue vigente. Dicha población se corresponde con un grupo social identificable por organizaciones criminales con móviles diversos. En tal posición, la vulnerabilidad de 
estos grupos sociales aumenta. En este caso, si se tiene en consideración la continuidad o repetitividad del fenómeno de violencia contra dicha población, ello puede relacionarse con factores como la impunidad persistente de los autores intelectuales, o la falta de políticas eficaces contra la criminalidad por parte de los organismos competentes. En últimas, una incapacidad institucional o tolerancia de hecho que permite la continuación de este tipo de eventos.

5. Pues bien, si existe un elemento en común entre los fenómenos descritos, parece ser la incapacidad o tolerancia de facto por parte de las instituciones. Pese a los avances en materia de persecución penal desde los organismos competentes, en la actualidad, los perpetradores continúan victimizando a los grupos sociales.

6. En este estado de cosas, resulta necesario un llamado de atención para el reconocimiento de la gravedad en los ámbitos nacional e internacional. Un llamado urgente por el respeto a los derechos humanos de toda la población, que no se limite a las organizaciones defensoras de derechos humanos. Un llamado a dejar de normalizar la violencia en la conciencia de los ciudadanos. Finalmente, reconocer la gravedad de los fenómenos supone un paso elemental para la reconstrucción de la memoria histórica, y la convivencia social.

\section{Referencias}

Ambos, K. (2013). Crímenes de lesa humanidad y Corte Penal Internacional. Cuadernos de Derecho Penal 9: 95-140.

BBC. (10 junio 2019). La "guerra por el narcotráfico" en Colombia entre el ELN y los paramilitares del Clan del Golfo que obligó a 7 pueblos a huir y abandonarlo todo. Recuperado de https://www.bbc.com/mundo/noticias-america-latina-48536482 (02/02/2021).

BBC. (22 mayo 2020). Colombia: cómo los grupos armados están aprovechando la cuarentena para seguir asesinando activistas. https://www.bbc.com/mundo/ noticias-america-latina-52761318 (02/02/2021).

Benería, L. y Sarasúa, C. (2011). Delitos y crímenes económicos contra la humanidad. Revista de Economía crítica, 12(12), pp. 156-159.

Bolívar, E. (2011). Crímenes de lesa humanidad en el derecho penal internacional. Principia luris, 15, pp. 159-175.

Castellanos, L. A. y Barragán, D. (2016). Caracterización jurídica del crimen de lesa humanidad: Estudio de caso del homicidio de Bernardo Jaramillo Ossa. Diálogos de Saberes: Investigaciones y Ciencias Sociales 45, pp. 69-87. 
Cepeda, I. (2006). Genocidio político: el caso de la Unión Patriótica en Colombia. Revista Cetil, 1(2), pp. 101-112.

Centro de Investigación y Educación Popular (CINEP) et al. (2018). ¿Cuáles son los patrones? Asesinatos de líderes sociales en el Post Acuerdo. Recuperado de https://www.cinep.org.co/publicaciones/es/producto/cuales-son-los-patronesasesinatos-de-lideres-sociales-en-el-post-acuerdo/ (20/06/19).

Centro Nacional de Memoria Histórica (CNMH). (2014). Silenciar la democracia. Las masacres de Remedios y Segovia 1982-1997. Recuperado de http://www. centrodememoriahistorica.gov.co/2014-01-29-15-08-26/silenciar-la-democracialas-masacres-de-remedios-y-segovia (20/06/19).

Centro Nacional de Memoria Histórica (CNMH). (2018). Todo pasó frente a nuestros ojos. El genocidio de la Unión Patriótica 1984-2002. Recuperado de http://www. centrodememoriahistorica.gov.co/informes/publicaciones-por-ano/2018/todopaso-frente-a-nuestros-ojos-genocidio-de-la-union-patriotica-1984-2002 (20/06/19).

Defensoría del Pueblo Colombia. (2017). Informe especial de riesgo: Violencia y amenazas contra los líderes sociales y los defensores de derechos humanos. Recuperado de http://desarrollos.defensoria.gov.co/desarrollo1/ABCD/bases/marc/documentos/ textos/INFORME_ESPECIAL_LIDERES_30-03-17_(1).pdf (31/08/19).

Defensoría del Pueblo Colombia. (2018). Alerta temprana 026-2018 es una nota de seguimiento al informe de Riesgo 010-2017. Recuperado de http://www.defensoria. gov.co/es/nube/destacados/7076/Alerta-temprana-026-2018-es-una-nota-deseguimiento-al-informe-de-Riesgo-010-2017.htm?_s=dia_agua (31/08/19).

Dudley, S. (2008). Armas y urnas: historia de un genocidio político. Bogotá: Editorial Planeta.

El País. (28 diciembre de 2017). La verdad incompleta del paramilitarismo en Colombia. https://elpais.com/internacional/2017/12/16/colombia/1513441839_413675.html $(02 / 02 / 2021)$.

Esparza, M. (2009). "Introduction: globalizing Latin American studies of state violence and genocide". En Esparza, Huttenbach y Feierstein (Eds.), State Violence and Genocide in Latin America: The Cold War Years. (pp.1-20). Routledge.

Esparza, M., Huttenbach, H. y Feierstein, D. (eds.). (2009). State Violence and Genocide in Latin America: The Cold War Years. Routledge.

Estrada, J. (2015). Acumulación capitalista, dominación de clase y rebelión armada. Elementos para una interpretación histórica del conflicto social y armado. Comisión histórica del conflicto y sus víctimas. Bogotá: Universidad Nacional de Colombia.

Feierstein, D. (2014). Genocide as social practice: reorganizing society under the Nazis and Argentina's military juntas. Rutgers University Press.

Feierstein, D. (2015). Juicios: sobre la elaboración del genocidio II. México, D.F: Fondo de Cultura Económica.

Feierstein, D. (2016). El concepto de genocidio y la 'destrucción parcial de los grupos nacionales'. Revista Mexicana de Ciencias Políticas y Sociales Nueva Época 61, (228), pp. 247-266.

Fernández, A., Sánchez, Á., y Ortega, J. (2015). Curso de derecho internacional público. Tirant lo Blanch.

Gándara, M. (2013). Hacia un pensamiento crítico en derechos humanos: aportes en diálogo con la teoría de Joaquín Herrera Flores. (Tesis doctoral publicada). Universidad Pablo de Olavide. 
Garretón, R. (2001). La protección de los derechos humanos y los crímenes de lesa humanidad y genocidio. La responsabilidad del individuo. En XII Seminario Duque de Ahumada, Crímenes contra la Humanidad y Genocidio. (pp.17-33). Madrid: Ministerio del Interior, Secretaría General Técnica.

Gil, Alicia. (2003). Los crímenes contra la humanidad y el genocidio en el estatuto de la Corte Penal Internacional. Revista de Derecho Penal, 1, pp. 215-270.

Gil, Alicia. (2016). Crímenes contra la humanidad. EUNOMÍA. Revista Cultura de la Legalidad, 10, pp. 202-215.

Gil, Alicia. (2017). El tratamiento jurídico de los crímenes cometidos en el conflicto armado colombiano. La problemática jurídica en el marco de la dicotomía pazjusticia. En Gil, A., Maculan, E., Ferreira, S. (Eds), Colombia como nuevo modelo para la justicia de transición. (pp.21-52). Madrid: Instituto Universitario General Gutiérrez Mellado IUGM.

Gil, Alicia. (2019). El tipo subjetivo del delito de genocidio: especial atención a la figura del dolo eventual. En Olasolo, De Prada (Coords.). La evolución de la definición y aplicación del delito de genocidio. La contribución iberoamericana y el legado del Tribunal Penal Internacional para la ex Yugoslavia (vol. 9). (pp.453-496). Tirant lo Blanch.

Gómez Isa, F. (dir.). (2008). Colombia en su laberinto: una mirada al conflicto. Madrid: Los Libros de la Catarata.

Gómez Suárez, A.. (2013). La coyuntura geopolítica genocida de la destrucción de la Unión Patriótica (1985-2010). Estudios Políticos, 43, pp. 180-204.

Gutiérrez, F., y Barón, M. (2006). Estado, control territorial paramilitar y orden político en Colombia. En Gutiérrez. F (Coord.), Nuestra guerra sin nombre. Transformaciones del conflicto en Colombia. (pp.267-312). Bogotá: Norma.

Herrera Flores, J. (2008). La reinvención de los derechos humanos. Sevilla: Atrapasueños.

Huertas, O., y Cáceres, V. (2015). Genocidio político y derecho penal internacional: análisis desde su exclusión típica política. Revista Brasileira de Estudos Jurídicos, 10(2), pp. 173- 195.

Instituto de Estudios para el Desarrollo y la Paz (INDEPAZ). (2019). Informe parcial julio 26 de 2019. http://www.indepaz.org.co/wp-content/uploads/2019/08/Informeparcial-Julio-26-2019-Indepaz-Marcha-Cumbre.pdf (29/08/19).

Koessl, M. (2015). Violencia y habitus: paramilitarismo en Colombia. Bogotá: Siglo del Hombre Editores.

Liñán, A. (2015). El crimen contra la humanidad. Dykinson.

Liñán, A. (2017). La interpretación del término "población civil" como elemento del tipo en el crimen contra la humanidad". Revista Penal, 40: 168-182.

Liñán, A. (2019). Similitudes y diferencias entre el delito de genocidio y el crimen contra la humanidad. En Olasolo, de Prada (Coords.). La evolución de la definición y aplicación del delito de genocidio. La contribución iberoamericana y el legado del Tribunal Penal Internacional para la ex Yugoslavia (vol. 9). (pp. 365-398). Tirant lo Blanch.

Oficina del Alto Comisionado de las Naciones Unidas para los Derechos Humanos en Colombia (OACNUDH). (2019). Informe del Alto Comisionado de las Naciones Unidas para los Derechos Humanos sobre la situación de derechos humanos en Colombia durante el año 2018. Recuperado de https://www.hchr.org.co/index.php/ informes-y-documentos/informes-anuales/9017-informe-del-alto-comisionado- 
de-las-naciones-unidas-para-los-derechos-humanos-sobre-la-situacion-dederechos-humanos-en-colombia-durante-el-ano-2018 (28/08/19).

Olasolo, H.,Chinchón, J. y Rodríguez, A. (2019). La definición del delito de genocidio en la convención de 1948, la contribución iberoamericana a su evolución y el legado del TPIY con respecto a la interpretación de su definición y aplicación. En Olasolo, De Prada (coords.), La evolución de la definición y aplicación del delito de genocidio. La contribución iberoamericana y el legado del Tribunal Penal Internacional para la ex Yugoslavia vol. 9, (pp.661-716). Tirant lo Blanch.

Ortiz, I. (2001). La desaparición forzada, una conducta de perpetración del genocidio político contra la Unión Patriótica. Pensamiento Jurídico, (14), pp. 271-285.

Ortiz, I. (2006). Genocidio político contra la Unión Patriótica: nuevas miradas para nuevas lecturas. Bogotá, DC: Universidad Nacional de Colombia.

Ortiz, I. (2009). El genocidio político contra la Unión Patriótica. Acercamiento metodológico para recuperar la historia de las víctimas, Bogotá: Universidad Nacional de Colombia.

Pizarro, E. (2003). Colombia. El proyecto de seguridad democrática de Álvaro Uribe. Nueva Sociedad, 186, pp. 4-17.

Roitman, M. (2017). Tiempos de oscuridad: historia de los golpes de Estado en América Latina. Madrid: Ediciones Akal.

Saldarriaga, D., y Gómez, M. (2015). Mujeres víctimas del genocidio contra la Unión Patriótica: ¿es posible su reparación integral? Revista Ratio Juris, 10(21), pp. 95-138.

Shaw, M. (2013). Genocide and international relations: Changing patterns in the transitions of the late modern world. Cambridge: Cambrige University Press.

Torres, C. (2015). Colombia siglo XX: Desde la Guerra de los Mil Días hasta la elección de Álvaro Uribe (2. ${ }^{\circ}$. Ed.). Bogotá : Editorial Pontificia Universidad Javeriana.

Valencia, H. y Zúñiga, L. (2015). La teoría del partisano de Carl Schmitt y el conflicto armado en Colombia. Postdata, 20(1), pp. 109-131. 